\title{
Economic Burden of Chronic Obstructive Pulmonary Disease Patients in Malaysia: A Longitudinal Study
}

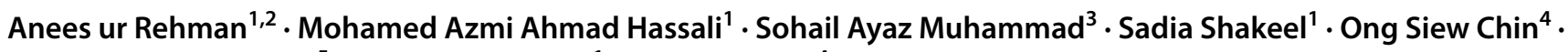 \\ Irfhan Ali Bin Hyder Ali ${ }^{5}$. Jaya Muneswarao ${ }^{1} \cdot$ Rabia Hussain ${ }^{4}$
}

Published online: 14 April 2020

(c) The Author(s) 2020

\begin{abstract}
Background Chronic obstructive pulmonary disease (COPD) requires long-term pharmacological and non-pharmacological management that encompasses continuous economic burden on patients and society, and also results in productivity losses due to compromised quality of life. Among working-age patients, COPD is the 11th leading cause of work productivity loss. Objective The aim of this study was to assess the economic burden of COPD in Malaysia, including direct costs for the management of COPD and indirect costs due to productivity losses for COPD patients.

Methodology Overall, 150 patients with an established diagnosis of COPD were followed-up for a period of 1 year from August 2018 to August 2019. An activity-based costing, 'bottom-up' approach was used to calculate direct costs, while indirect costs of patients were assessed using the Work Productivity and Activity Impairment Questionnaire.

Results The mean annual per-patient direct cost for the management of COPD was calculated as US\$506.92. The mean annual costs per patient in the management phase, emergency department visits, and hospital admissions were reported as US\$395.65, US $\$ 86.4$, and US\$297.79, respectively; 31.66\% of COPD patients visited the emergency department and $42.47 \%$ of COPD patients were admitted to the hospital due to exacerbation. The annual mean indirect cost per patient was calculated as US\$1699.76. Productivity losses at the workplace were reported as $31.87 \%$ and activity limitations were reported as $17.42 \%$.

Conclusion Drugs and consumables costs were the main cost-driving factors in the management of COPD. The higher ratio of indirect cost to direct medical costs shows that therapeutic interventions aimed to prevent work productivity losses may reduce the economic burden of COPD.
\end{abstract}

Anees ur Rehman

aneesurrehmanr90@gmail.com

1 Department of Clinical Pharmacy, School of Pharmaceutical Sciences, University Sains Malaysia, Penang, Malaysia

2 Faculty of Pharmacy, Bahauddin Zakariya University Multan, Punjab, Pakistan

3 School of Management Sciences, University Sains Malaysia, Penang, Malaysia

4 Department of Social and Administrative Pharmacy, School of Pharmaceutical Sciences, University Sains Malaysia, Penang, Malaysia

5 Respiratory Department, Hospital Pulau Penang, Ministry of Health Malaysia, Penang, Malaysia

\section{Key Points for Decision Makers}

The mean annual per-patient direct and indirect costs for the management of chronic obstructive pulmonary disease (COPD) were calculated as US\$506.92 and US\$1699.76, respectively.

The mean annual costs per patient in the management phase, emergency department visits, and hospital admissions were reported as US\$395.65, US\$86.4, and US\$297.79, respectively.

In COPD patients, the mean annual rate of outpatient visits, emergency department visits, and hospital admissions were calculated as $2.12,0.37$, and 0.87 visits per patient, respectively.

In COPD patients, productivity losses at the workplace were reported as $31.87 \%$ and activity limitations were reported as $17.42 \%$. 


\section{Introduction}

Chronic obstructive pulmonary disease (COPD) is a chronic respiratory disorder characterized by persistent and progressive airflow obstruction, affecting $6-10 \%$ of adults worldwide [1]. In the Asia-Pacific region, the prevalence of COPD was estimated as $6.2 \%$, among which one-fifth were experiencing severe or very severe COPD [2]. The World Health Organization (WHO) estimated that COPD prevalence will increase threefold in Asia, compared with the rest of world, until 2020 [3]. In Malaysia, approximately 448,000 cases were reported in 2010, with an estimated burden of Malaysian ringgit (MYR) 2.8 billion [4]. A 2012 International Tobacco Control Malaysia report reported a drastic increase in smoking in adult males (46.4\%) and a slight increase in females (1.6\%), which may result in an increase in the prevalence of COPD in Malaysia [5, 6]. COPD is the third major cause of morbidity and fifth leading cause of mortality worldwide [3]. The mortality burden of COPD is expected to rise to $8.6 \%$ by 2030 [7].

Preliminary evidence on COPD seems to suggest that this chronic condition is associated with a high economic burden. In 2012, COPD patients incurred approximately 14\% higher costs than non-COPD patients [8]. The direct cost of management of COPD varies from 35 to $75 \%$ of the total cost among different countries [9, 10]. COPD also results in significant economic burden to both the patient and society, resulting from productivity losses due to compromised quality of life, early retirement, and disability pension [11]. Among working-age patients, COPD is the eleventh leading cause of work productivity loss and is expected to be the seventh leading cause until 2030 [12]. In the US and UK, approximately $40-60 \%$ of patients diagnosed with COPD were of working age [13]. Employees diagnosed with COPD show a higher absenteeism rate and compromised work performance at the working place compared with those without COPD or employees with other chronic conditions, i.e. asthma and cardiovascular diseases $[14,15]$. The monthly per capita income of COPD patients was reported to be approximately $34.1 \%$ less than healthy workers due to absenteeism from the workplace [16]. COPD patients missed an average of 150 days per year from work and an average of 1.47 years of work due to early retirement; one-third of the family income was associated with the management of COPD [17]. Work productivity loss and absenteeism affects the national economy. Indirect costs due to work loss and early retirement range between 20 and $69 \%$ of the total economic burden of COPD depending on the social security policies of the countries [18].

Economic burden due to COPD varies substantially from country to country due to differences in the cost of medicines, resources utilized, labour costs related to health policies, and specialized management policies [9]. It requires years of continuous pharmacological and non-pharmacological treatment, as well as specialist staff for better supervision of patients, which encompasses continuous economic burden on patients [19].

Most of the research on the pharmacoeconomics of COPD comes from Europe and the US [9, 18]. Despite being a major health problem, existing data on the economic burden of COPD in Malaysia are limited. The Malaysian healthcare system is mostly financed by the government, without any burden on patients [20]. Assessing the cost of the management of COPD in a public hospital can help policy makers and government agencies with cost-efficient allocation of resources for the management of disease, and to find the key cost drivers and possible cost reduction areas in a cost-conscious environment. Moreover, the information and assumption of costs have focused on direct patient-related costs because indirect costs are mostly not available due to difficulties in identifying, measuring, and valuing. Neglecting indirect costs can result in underestimation of the exact economic burden of COPD [21, 22]. Thus, the objective of the current research was to assess the economic burden of COPD in Malaysia, including direct costs for the management of COPD and indirect costs due to productivity losses of COPD patients.

\section{Methodology}

This study was part of a prospective cohort that included patients from the main public hospital of Penang, Malaysia. Overall, 150 patients with an established diagnosis of COPD who attended the outpatient chest clinic for the management of stable disease, and/or who were rushed to the emergency department (ED) and/or admitted to the ward due to exacerbation in hospital, during May 2018 to August 2019, were included in this study (3 months for recruitment and 1-year follow-up). The data relating to cost were collected at every scheduled and unscheduled visit. The attributable cost of COPD was calculated as the sum of all amounts related to COPD events and COPD-related medicines. Malaysian official cost tariffs were used for cost calculations [23]. All costs were calculated in MYR and converted to 2019 US\$ (1 US $\$=4.13$ MYR on 18 September 2019) [24].

The inclusion criterion has been discussed elsewhere (publication under review). In brief, patients with a confirmed diagnosis of COPD [post-bronchodilator forced expiratory volume in $1 \mathrm{~s}\left(\mathrm{FEV}_{1}\right) /$ forced vital capacity $\left.(\mathrm{FVC})<0.70\right]$ and having an outpatient record of a minimum of 1 year were included in the study. $\mathrm{FEV}_{1}$ percentage predicted values were calculated based on reference values from the Global Lung Function Initiative [25], while the severity of COPD was defined based on the GOLD 2018 classification. 


\subsection{Data Collection}

Data collectors were recruited for data collection and trained by an academic investigator. A combination of validated tools and a self-developed interviewer-administered questionnaire (electronic supplementary material) was used to gather information regarding demographic data, social status, employment status, respiratory symptoms, exacerbation frequency, comorbidities [according to the Charlson Comorbidity Index $(\mathrm{CCI})$, healthcare resource utilization, and indirect cost of patients. Indirect cost was assessed using the Work Productivity and Activity Impairment Questionnaire: COPD-specific V2.0 (WPAI-COPD). Spirometry was also performed for all recruited patients at every visit, according to the American Thoracic Society's guidelines. The study protocol was approved by the National Medical Research Register, Malaysia, and the clinical research centre of the relevant hospital (registration number: NMRR-18-1482-42075). Written informed consent was obtained from all participants.

\subsection{Comorbidities}

Information regarding medical comorbidities was obtained from the patient's medical record file. The reported comorbidity was rated according to the CCI, which evaluates the comorbidity burden by weighing and summing the patientreported conditions (e.g. myocardial infarction, congestive heart failure, peripheral vascular disease, dementia, cerebrovascular accident, connective tissue disease, peptic ulcer, liver disease, diabetes mellitus, hemiplegia, chronic kidney disease, cancer, leukemia, lymphoma, and AIDS). A higher score indicates a greater comorbidity burden [26].

\subsection{Direct Costs}

The direct healthcare costs for the management of COPD were divided into maintenance costs for the ongoing care of patients with COPD and the additional costs for moderate (ED visit) or severe (hospitalization) exacerbations.

The activity-based costing (ABC) 'bottom-up' questionnaire was designed comprising items and resources used in the management of COPD. Traditional methods do not provide exact and accurate economic information. $\mathrm{ABC}$ can provide an accurate economic picture of the disease, and can assess the effect of cost on the quality of various services [27]. This approach was selected to ensure accuracy and transparency of results, as no national-level cost data were available for Malaysia. Different cost centers were identified from the literature search and by interviewing heads of departments at the study hospital. Different cost centers identified in the management of COPD were chest clinic, pathology laboratory, spirometry room, radiology laboratory, ED, outpatient pharmacy, inpatient pharmacy, and respiratory ward. All activities in the cost centers were observed prospectively to evaluate the direct cost. Activities involved were registration, screening, treatment, patient counselling, and prescription dispensing. In addition to these activities, two additional activity specialist visits and medication dispensing were also observed for hospital-admitted patients. Resources were identified as patient time of staff members for each activity, medication, diagnosis, consumables for drug delivery and oxygen therapy, inpatient stay, incubation, nebulization, equipment, building, stationery, electricity, and cleaning. Costs from these cost centers, along with the unit prices for the services provided, were calculated and incurred directly to the patients receiving the services.

\subsubsection{Human Resources}

Personnel costs comprise the time spent by physicians, specialists, pharmacists, paramedical staff, administrative staff, and technical staff in different cost centers. The time spent by health professionals for spirometry, laboratory services, checkup, and pharmacy services, both in the chest clinic and during hospitalization, was estimated. A time and motion study on the ABC method was used to estimate the human resource cost for each service. Patients at the chest clinic, ED, outpatient pharmacy, inpatient pharmacy, spirometry room, radiology room, laboratory, and chest ward were observed, to measure the time for completion of each activity. The total human resource cost for an activity was calculated as the sum of all human resource costs involved in a specific activity. The personnel time cost for each employee involved was calculated according to the pay scale system of the Federal Civil Services Officers under the System of Remuneration Malaysia [28]. Unit costs per minute were calculated by dividing the employee's yearly salary by the number of productive working minutes per year. Productive working minutes were based on the average number of shifts per month, excluding annual leave and sick leave. The number of minutes spent on each patient was combined with staff costs per minute. The manpower involved in different cost centers is shown in Fig. 1.

\subsubsection{Medication and Consumables}

Prescription records from every visit made by the patients were collected from their medical files. Medicines were classified according to classes. The quantity, frequency, and duration of each prescribed drug and inhaler were recorded. Prescriptions were differentiated based on outpatient visits (management phase) and hospitalization (exacerbation phase). Information regarding consumables (syringes, cotton swabs, etc.) used in a diagnostic test was collected by following the complete activity. The unit prices of drugs 
were based on the standard government drugs price list [29]. The total cost of consumables was calculated by adding the cost of all consumables used in the specific test/ service.

\subsubsection{Building and Equipment Used for Activities (Consultation, Diagnosis, Pharmacy)}

The square footage of the hospital building that used for a specific activity was measured. The costs relating to the building used were calculated by multiplying the area of the specific cost center by the per unit cost of a public building in Malaysia (MYR 85/ $\mathrm{ft}^{2}$ ). The number of activities performed per year, i.e. consultations, diagnosis, and admissions, was obtained from patient registers, while maintenance costs and unit costs of diagnostics and devices used were obtained from the hospital's Finance Department. Total yearly equipment utilization by COPD patients was obtained from the laboratory register, and the interest rate was obtained from the National Bank of Malaysia. The useful lifespan of laboratory equipment was assumed to be 5 years [30]. Moreover, straight-line depreciation, with a discount rate of $3 \%$, was used. At the end of the asset's useful lifespan, the resale value was considered to be $10 \%$ of the initial cost [30].

The cost of electricity, sanitation, and stationary used in the clinic was obtained from the Administration Department. To obtain the per-patient cost, the cost of electricity, sanitation, and stationary utilized in 1 year was divided by the total number of patients treated in the clinic in 1 year. Direct nonmedical costs included transportation costs, which were calculated by estimating the mean two-way distance from home to hospital (patients were asked the approximate distance of their home from the hospital) and multiplying it by the government-approved per kilometer cost (US\$0.13/km) [31].

\subsubsection{Exacerbation Phase}

Costs pertaining to the exacerbation phase were divided into ED visit (moderate exacerbation) and hospitalization (severe exacerbation) costs. ED visits followed by hospital admissions were included in the hospital admission cost instead of the ED visit cost. The hospitalization cost was calculated as the sum of personnel, medicine, diagnostic test, building, furniture, and hotel (bed and food) costs. For admitted patients, length of stay in the ward or intensive care unit was observed prospectively. Daily bed and food costs were obtained from the hospital's Finance Department (MYR 285) [31]. Unit costs were also obtained from the hospital's Finance Department and multiplied by the number of utilized units.

The total direct cost was the sum of the management and exacerbation costs. As not all patients suffered from exacerbation, the estimated cost was corrected for the proportion of patients who suffered from exacerbation before the total cost estimation.

\subsection{Indirect Costs}

WPAI-COPD is a reliable and validated questionnaire used in many diseases. It measures the amount of absenteeism (work time lost due to COPD), presenteeism (reduced productivity due to disease while at work), and activity impairment (restriction in daily activities). Indirect costs were calculated in terms of activity limitation for all COPD patients and productivity losses for employed patients. The average monthly salary per person was obtained from the official website of the Statistics Department of the Malaysian Government [23]. The latest statistics were available for 2017. Patients completed the WPAI-COPD questionnaire at each visit. The recall period for this questionnaire was 7 days. The average missing hours per week were calculated and multiplied by 52 .
Fig. 1 Human resources in different cost centres

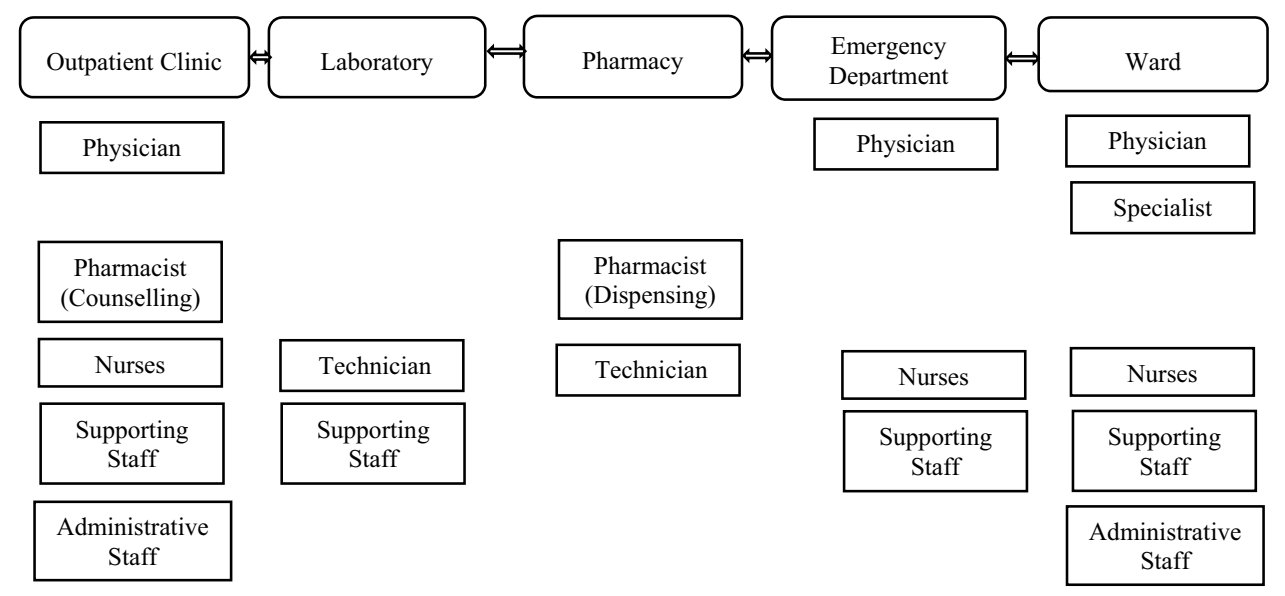




\subsection{Statistical Analysis}

Frequencies and percentages were calculated for categorical variables, and mean and standard deviation were reported for continuous variables. Means were calculated for medical and pharmacy costs. Statistical analyses were performed using IBM SPSS Statistics version 24.0 (IBM Corporation, Armonk, NY, USA).

\section{Results}

Among 150 included patients, five were lost to follow-up for different reasons (moved from the city, changed hospital, surgery). The majority of patients $(69.24 \%)$ were male, with a mean age of 69.71 years (6.62). The mean $\mathrm{FEV}_{1}$ percentage predicted and $\mathrm{FEV}_{1} / \mathrm{FVC}$ were reported as 57.13 (12.52) and 54.21 (11.32), respectively. Approximately $77.41 \%$ of patients were ex-smokers, $12.38 \%$ were current smokers, and $10.21 \%$ were non-smokers. Mean body mass index (BMI) was reported as $24.14 \mathrm{~kg} / \mathrm{m}^{2}$ (4.67). Comorbidities were reported in approximately $65.32 \%$ of patients. Among patients having comorbid conditions, $68.39 \%$ reported the presence of one comorbid condition, $20.54 \%$ reported the presence of two comorbid conditions, and $11.07 \%$ reported the presence of three or more comorbidities. The mean Charlson Comorbidity Index was reported as 2.3 (3.4), and the mean annual per-patient direct cost for the management of COPD was calculated as US\$506.92. Sociodemographic and clinical characteristics of the COPD patients included in the study are displayed in Table 1.

\subsection{Maintenance Phase}

The average number of outpatient visits was 2.12 (1.3) per patient per year. The mean annual cost per patient in the management phase was reported as US\$395.65. In detail, the cost of drugs and consumables (laboratory chemicals, syringes, incubation masks, etc.) was highest (US\$349.71), followed by personnel (US\$32.24), equipment (US\$4.63), building (US\$3.38), depreciation (US\$2.57), electricity (US\$1.49), cleaning (US\$0.43), fixed assets (US\$0.84), and communication (US\$0.11). The mean cost in different cost centres during the maintenance phase is displayed in Table 2

\subsection{Exacerbation Phase}

The mean annual cost in different cost centers during the exacerbation phase is displayed in Table 3. During the study period, $31.66 \%$ of COPD patients visited the ED due to COPD exacerbation. On average, 0.38 visits to the hospital ED were reported for each patient annually. The mean annual cost of ED visits per patient was calculated as US\$86.4. During ED visits, the inpatient stay cost was highest (US\$38.43), followed by drugs and consumables (US\$30.02), personnel (US\$8.83), equipment (US\$5.89), building (US\$1.03), electricity and water (US\$0.62), fixed assets (US\$0.45), depreciation (US\$0.44), cleaning (US\$0.35), stationery (US\$0.30), and communication (US\$0.04).

In COPD patients, the average annual rate of hospitalization was calculated as 0.87 per patient. Almost $42.47 \%$ of COPD patients were admitted to the hospital due to COPD exacerbation, during the study period. The mean hospital stay was reported as 4.31 days, and the mean annual cost of hospitalization per patient was calculated as US\$297.79. During hospital admissions, the inpatient stay cost was highest (US\$139), followed by drugs and consumables (US\$88.27), personnel (US\$32.99), building maintenance (US\$10.68), equipment (US\$9.45), electricity and water (US\$6.01), cleaning (US\$4.48), depreciation (US\$2.53), fixed assets (US\$2.84), communication (US\$1.33), and stationery (US\$0.21). A comparison of different cost centers

Table 1 Sociodemographic and clinical characteristics of COPD patients

\begin{tabular}{ll}
\hline BMI, kg/m ${ }^{2}$ [mean (SD)] & $24.14(4.67)$ \\
Sex $(\%)$ & 69.24 \\
Male & 30.76 \\
Female & $69.71(6.62)$ \\
Age, years [mean (SD)] & \\
Working status (\%) & 40.27 \\
Retired & 43.19 \\
Full-time & 16.54 \\
Part-time & \\
Smoking status $(\%)$ & 12.38 \\
Current smoker & 77.41 \\
Ex-smoker & 10.21 \\
Non-smoker & $6.7(5.23)$ \\
Years with COPD [mean (SD)] & $57.13(12.52)$ \\
FEV $\%$ predicted [mean (SD)] & $54.21(11.32)$ \\
FEV ${ }_{1} /$ FVC [mean (SD)] & $2.3(3.4)$ \\
CCI & \\
Percentage of patents according to severity of COPD & \\
GOLD Grade I [\% $(n)]$ & $16.60(25)$ \\
GOLD Grade II [\% $(n)$ ] & $29.33(44)$ \\
GOLD Grade III [\% $(n)]$ & $35.33(53)$ \\
GOLD Grade IV [\% $(n)]$ & $18.67(28)$ \\
\hline
\end{tabular}

$B M I$ body mass index, $C O P D$ chronic obstructive pulmonary disease, $C C I$ Charlson Comorbidity Index, $F E V_{1}$ forced expiratory volume in $1 \mathrm{~s}, F V C$ forced vital capacity, GOLD $1 \mathrm{FEV}_{1} \geq 80 \%$ predicted, GOLD II FEV 1 50-80\% predicted, GOLD III $\mathrm{FEV}_{1}$ 30-50\% predicted, GOLD IV $\mathrm{FEV}_{1}<30 \%$ predicted, $S D$ standard deviation 
during the maintenance phase, ED visit, and hospital admissions in the management of COPD is shown in Fig. 2.

\subsection{Indirect Costs}

The annual mean indirect cost per patient was calculated as US\$1699.76 for COPD and US\$377.72 for other reasons. Productivity losses at the workplace were reported as $31.87 \%$ and activity limitations were reported as $17.42 \%$. The mean annual cost of transportation per COPD patient to attend outpatient visits, ED visits, and hospitalization was calculated as US $\$ 8.57$. The mean indirect cost of patients is displayed in Table 4.

\section{Discussion}

This study covers complete information regarding the economic burden of COPD from both a patient and societal prospective, including direct and indirect costs. The direct costs were calculated using 1-year of $\mathrm{ABC}$ for all services and service centers utilized in the management of COPD during the maintenance and exacerbation phases. The ABC 'bottom-up' approach ensures identification of all resources directly employed for patients in providing healthcare services, resulting in patient-specific unit costs.

Emergency visits or hospitalization indicate a degree of uncontrolled symptoms or exacerbation of COPD symptoms. Approximately $31.66 \%$ of patients visited the ED and $28.47 \%$ of patients were admitted to hospital due to uncontrolled symptoms. This suggests that symptoms were not properly controlled in these patients, even after regularly visiting health professionals. Grade 2 patients more frequently visited the ED compared with grade 3 and 4 patients. ED visits decreased as the disease progressed. The reason behind this may be the fact that COPD patients become selfrestrained to their symptoms with the passage of time, and only make unscheduled visits when they had severe problems. Barnes et al. reported that $39 \%$ of COPD patients with a longer disease history adopted a 'wait and see' policy to an exacerbation before seeking medical help [32].

Among the study participants, $59.73 \%$ were currently employed. COPD showed a substantial effect on the work productivity of patients. For full-time employees, indirect costs did not directly affect patients, but did affect the workplace in terms of work productivity loss. Long periods of cough and dyspnea were reported to have a substantial effect on the work performance of employed patients. Indirect costs are a modifiable cost component that can be significantly reduced by the use of optimal therapy and timely interventions from the health care system. In a survey of European asthma patients, work productivity loss was reduced by $19.3 \%$ to $36.2 \%$, depending on whether the

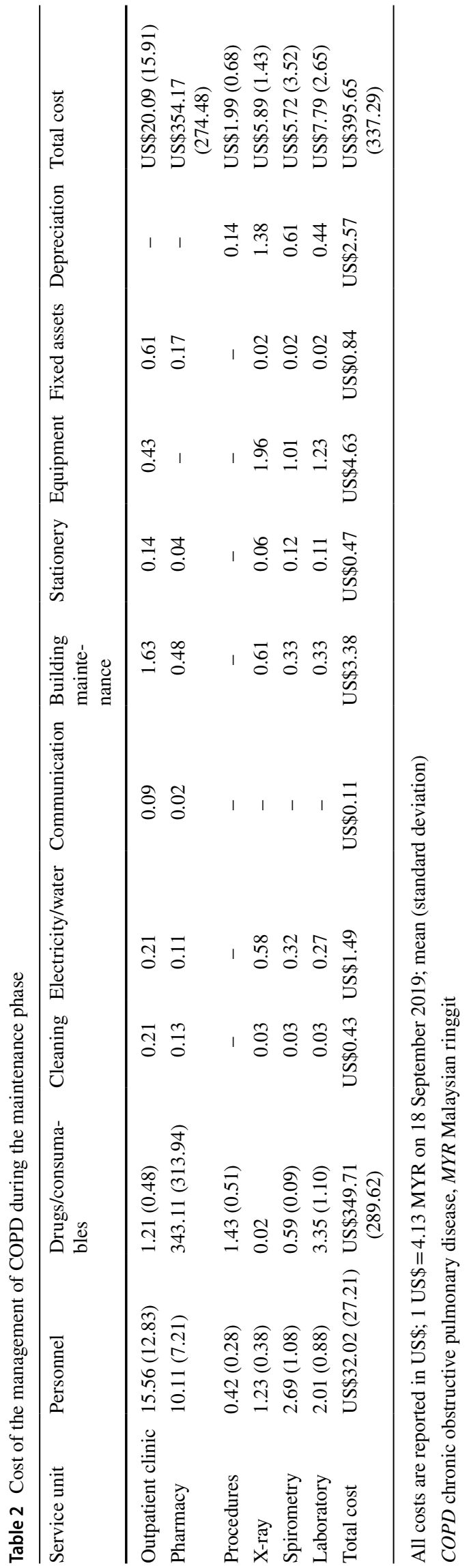




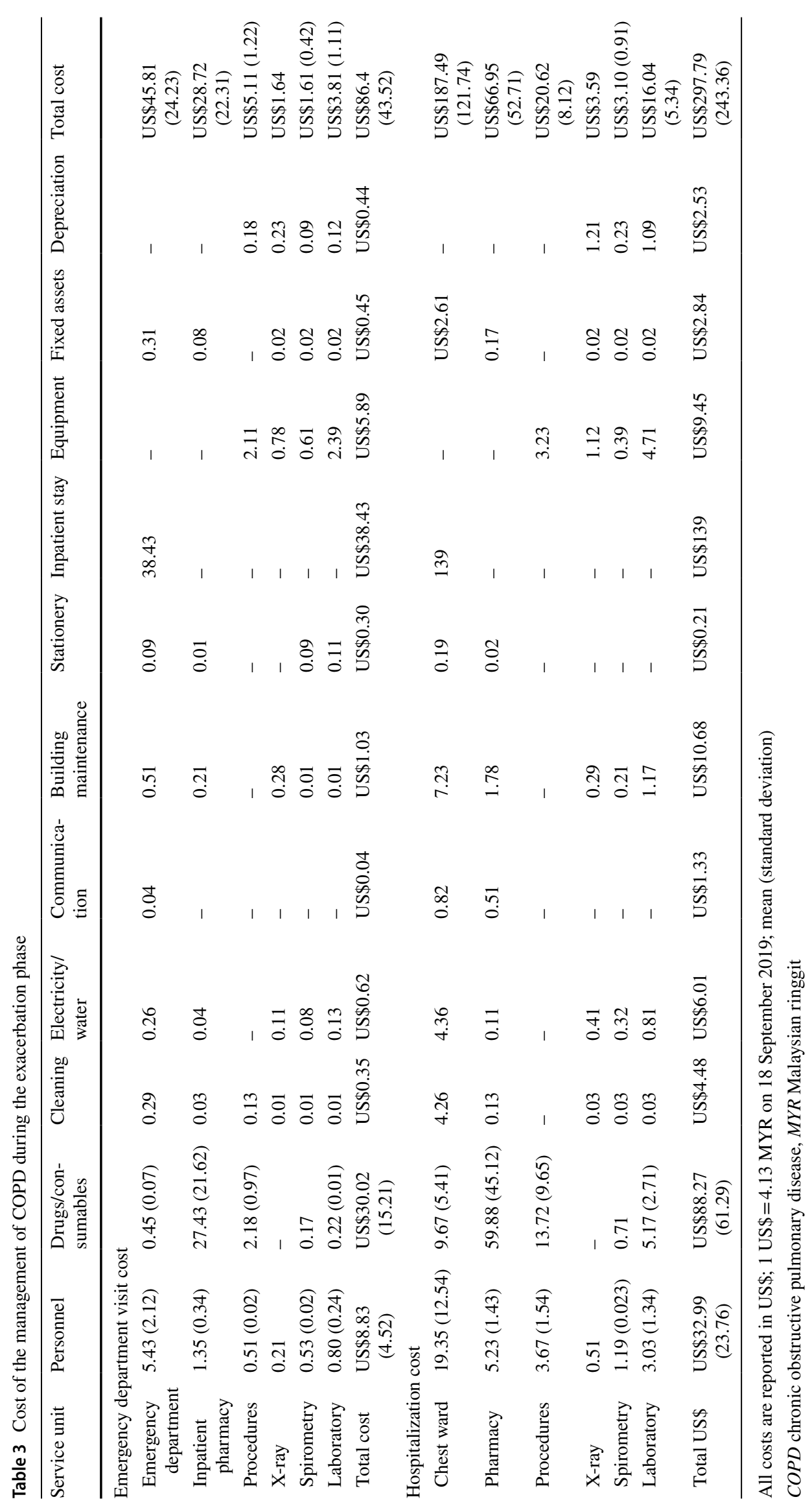


Fig. 2 a Comparison of different cost centres during the maintenance phase, ED visit, and hospital admissions in the management of COPD. b Comparison of different cost centres during the maintenance phase, ED visit, and hospital admissions in the management of COPD. 'Others' include cleaning, electricity/water, communication, building maintenance, stationery, equipment, fixed assets, and depreciation costs; procedures and ventilation. $E D$ emergency department, $C O P D$ chronic obstructive pulmonary disease

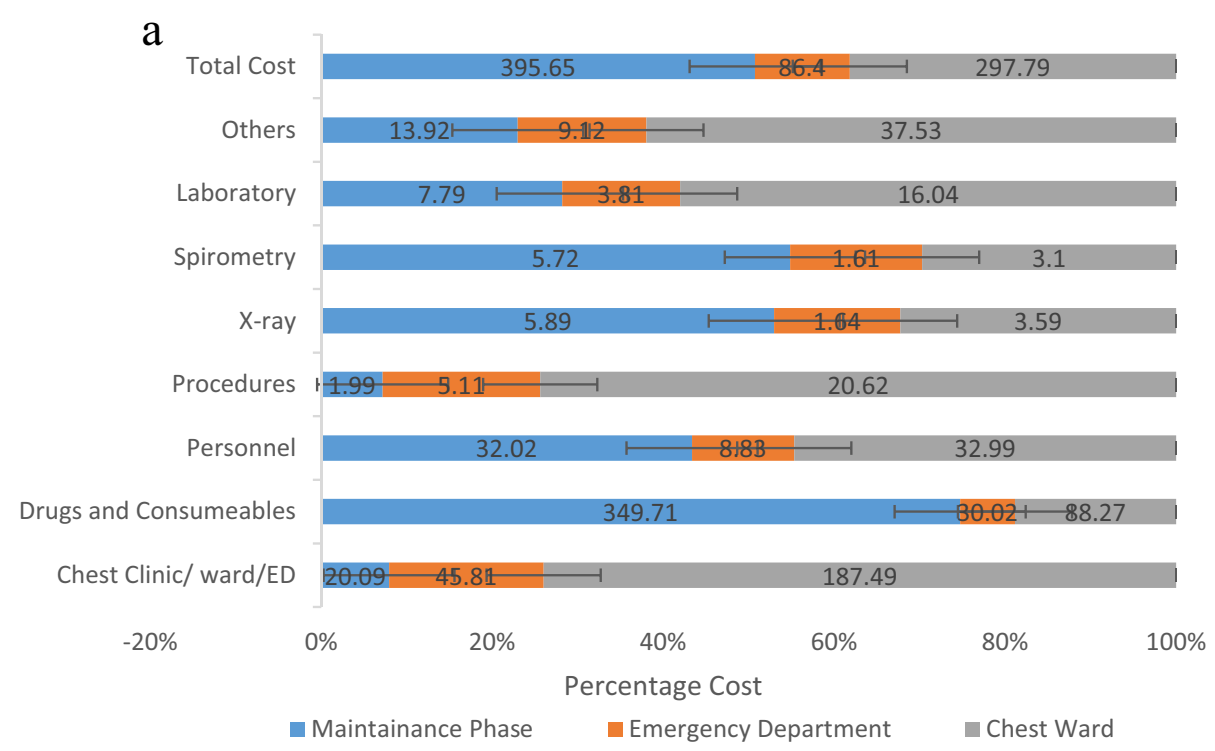

b

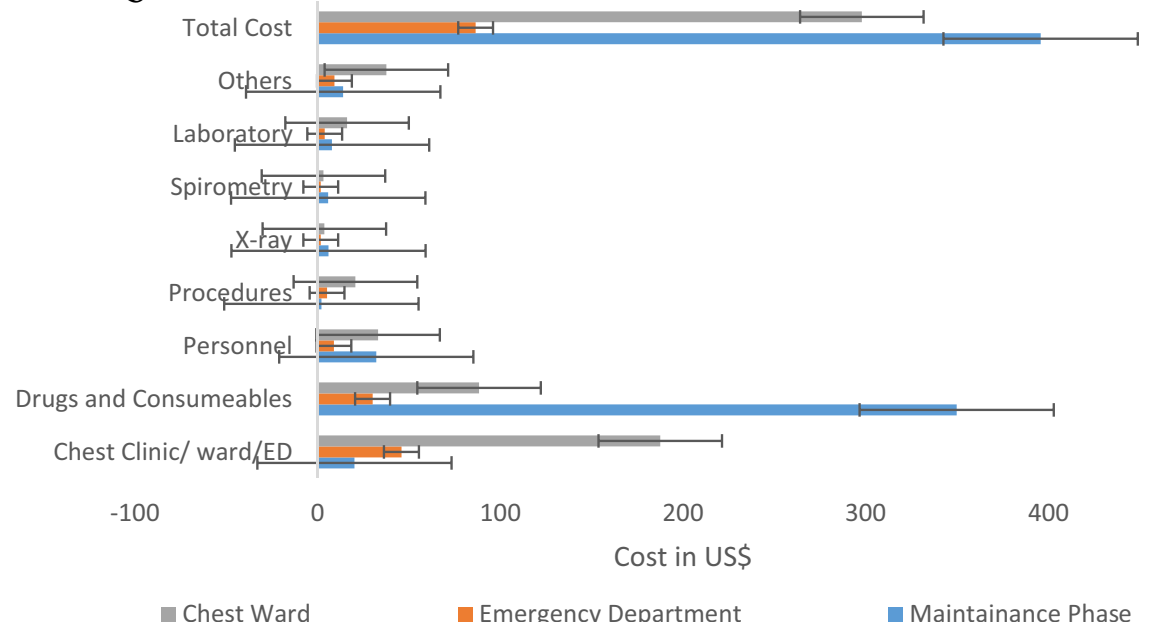

500
Table 4 Indirect cost of COPD patients

\begin{tabular}{ll}
\hline Indirect cost of patients & \\
\hline Missing hour due to COPD & $468.17(143.73)$ \\
Indirect cost due to COPD & US\$1699.76 (627.26) \\
Missing hours due to other reasons & $104.21(34.07)$ \\
Indirect cost due to other reasons & US\$377.72(113.28) \\
Productivity loss due to COPD & $31.87 \%(9.98)$ \\
Activity limitation due to COPD & $17.42 \%(6.59)$
\end{tabular}

All costs are reported in US\$; 1 US\$ $=4.13$ MYR on 18 September 2019; mean (standard deviation)

$C O P D$ chronic obstructive pulmonary disease, MYR Malaysian ringgit disease was well-controlled or not [32]. Self-management, pulmonary rehabilitation programs, smoking cessation, and workplace adaptations can help in the management of cough and dyspnea, thus improving the quality of life of patients and decreasing economic burden [13, 33]. It was estimated that a $20 \%$ reduction in productivity loss in Spain could result in annual savings of $€ 2.9$ billion, and a reduction in loss of work productivity in Sweden equivalent to 1 working day would generate an annual savings of $€ 528$ million [34].

One of the main strengths of our study is the use of the ABC 'bottom-up' approach to calculate direct costs. This approach provides more detailed information on all the resources associated with the management of disease and implementation of an intervention. It sheds light on the importance of different activities and their association with cost, and thus provides a better space for policy 
makers to make decisions regarding budget allocation and to improve management. Moreover, calculation of indirect costs in hours per week instead of days per week resulted in more accurate evaluation. Many national pharmacoeconomic guidelines recommend considering the impact of the societal benefit of intervention before considering it to be cost effective, especially for a disease such as COPD, which creates a substantial economic burden. Therefore, including indirect costs can provide an opportunity for researchers to compare the social welfare impact of future interventions in cost-effectiveness studies related to COPD.

Despite several strengths of this study, a few limitations should be considered when interpreting the results. The data used in this study only reflect the public healthcare system and may not reflect the management costs in private healthcare systems. The actual costs in private healthcare systems may vary, resulting in underestimation of the economic burden of COPD. However, the study population is likely to be representative of the general population as the public healthcare system provides health services to approximately $65 \%$ of the Malaysian population [20]. Moreover, we used tariff-based cost estimates applicable across Malaysia, which improves the generalizability of our findings. The cost of non-prescribed medications and indirect costs due to productivity losses of caregivers were excluded from the study, suggesting that COPD may have a higher economic burden than that reported.

\section{Conclusions}

This study covers the complete information regarding the economic burden of COPD, from both a patient and societal perspective, including direct and indirect costs. During the maintenance phase of COPD management, drugs and consumables costs were highest, followed by personnel and laboratory costs. During ED visits and hospital admissions, inpatient stay costs were highest, followed by drugs and consumables costs and personnel costs. Drugs and consumables costs were the main cost-driving factors in the management of COPD. In COPD patients, the mean annual rate of outpatient visits, ED visits, and hospital admissions were calculated as $2.12,0.37$, and 0.87 visits per patient, respectively; $31.66 \%$ of COPD patients visited the ED, and $42.47 \%$ of COPD patients were admitted to hospital due to exacerbation. This suggests that symptoms were not properly controlled in these patients, even after regularly visiting health professionals.

Among the study participants, $59.73 \%$ were currently employed. COPD showed a substantial effect on the work productivity of patients. For full-time employees, indirect costs did not directly affect patients, but did affect the workplace in terms of work productivity loss. Productivity losses at the workplace were reported as $31.87 \%$ and activity limitations were reported as $17.42 \%$. Work productivity loss can be controlled by better control of symptoms, which can result in substantial savings to the country's economy.

Acknowledgements The authors would like to thank the DirectorGeneral of Health, Malaysia, for his permission to publish this study. They are also thankful to the patients and staff from the Chest Clinic of the Penang Hospital.

Author Contributions AR, MAAH, and SAM made substantial contributions to the conception and design of this study, along with analysis and interpretation of the data. AR and SAM made substantial contributions to the analysis and interpretation of the data. SS, OSC, IABHA, $\mathrm{JM}$ and $\mathrm{RH}$ helped to address the comments during the revision process. All authors drafted the work or revised it critically for important intellectual content, and reviewed, critiqued, and approved the final version submitted for publication.

Data Availability Statement Data are available upon request from the corresponding author.

\section{Compliance with Ethical Standards}

Funding No funding was received from any sources for this project.

Conflict of Interest Anees ur Rehman, Mohamed Azmi Ahmad Hassali, Sohail Ayaz Muhammad, Sadia Shakeel, Ong Siew Chin, Irfhan Ali Bin Hyder Ali, Jaya Muneswarao, and Rabia Hussain declare they have no known competing financial interests or personal relationships that could have appeared to influence the work reported in this paper.

Open Access This article is licensed under a Creative Commons Attribution-NonCommercial 4.0 International License, which permits any non-commercial use, sharing, adaptation, distribution and reproduction in any medium or format, as long as you give appropriate credit to the original author(s) and the source, provide a link to the Creative Commons licence, and indicate if changes were made. The images or other third party material in this article are included in the article's Creative Commons licence, unless indicated otherwise in a credit line to the material. If material is not included in the article's Creative Commons licence and your intended use is not permitted by statutory regulation or exceeds the permitted use, you will need to obtain permission directly from the copyright holder.To view a copy of this licence, visit http://creativecommons.org/licenses/by-nc/4.0/.

\section{References}

1. Buist AS, McBurnie MA, Vollmer WM, Gillespie S, Burney P, Mannino DM, et al. International variation in the prevalence of COPD (the BOLD Study): a population-based prevalence study. Lancet. 2007;370(9589):741-50.

2. Lim S, Lam DCL, Muttalif AR, Yunus F, Wongtim S, Shetty V, et al. Impact of chronic obstructive pulmonary disease (COPD) in the Asia-Pacific region: the EPIC Asia population-based survey. Asia Pacific Fam Med. 2015;14(1):4

3. Mathers CD, Loncar D. Projections of global mortality and burden of disease from 2002 to 2030. PLoS Med. 2006;3(11):e442.

4. Hassan HA, Aziz NA, Hassan Y, Hassan F. Does the duration of smoking cessation have an impact on hospital admission and 
health-related quality of life amongst COPD patients? Int J Chron Obstr Pulmonary Dis. 2014;9:493.

5. Board MHP. ITC Malaysia National Report: findings from Wave 1 to 4 surveys (2005-2009). 2012. Available at: https://www.mysih at.gov.my/v2/promosi/images/stories/pusatmaklumat/itcreport. Accessed Sep 2019.

6. Shahab L, Jarvis M, Britton J, West R. Prevalence, diagnosis and relation to tobacco dependence of chronic obstructive pulmonary disease in a nationally representative population sample. Thorax. 2006;61(12):1043-7.

7. WHO. World Health Statistics 2018. World Health Organization. 2019. Available at: https://apps.who.int/iris/bitstream/handl e/10665/272596/9789241565585-eng.pdf.

8. D'Souza AO, Shah M, Dhamane AD, Dalal AA. Clinical and economic burden of COPD in a medicaid population. COPD. 2014;11(2):212-20.

9. ur Rehman A, Ahmad Hassali MA, Muhammad SA, Shah S, Abbas S, Hyder Ali IAB, et al. The economic burden of chronic obstructive pulmonary disease (COPD) in USA, Europe and Asia: results from a systematic review of the literature. Expert Rev Pharmacoecon Outcomes Res. Epub 18 Oct 2019.

10. Shah S, Abbas G, Hanif M, Rehman A, Zaman M, Riaz N, et al. Increased burden of disease and role of health economics: Asia-pacific region. Expert Rev Pharmacoecon Outcomes Res. 2019;19(5):517-28.

11. Ding D, Kolbe-Alexander T, Nguyen B, Katzmarzyk PT, Pratt M, Lawson KD. The economic burden of physical inactivity: a systematic review and critical appraisal. Br J Sports Med. 2017;51(19):1392-409.

12. WHO. Measurement of Healthy Life Expectancy and Wellbeing. Geneva: World Health Organization; 2019. Available at: https:// www.who.int/healthinfo/sage/meeting_reports/en/.

13. Rai KK, Adab P, Ayres JG, Siebert WS, Sadhra SS, Sitch AJ, et al. Factors associated with work productivity among people with COPD: Birmingham COPD Cohort. Occup Environ Med. 2017;74(12):859-67.

14. Holden L, Scuffham PA, Hilton MF, Ware RS, Vecchio N, Whiteford HA. Which health conditions impact on productivity in working Australians? J Occup Environ Med. 2011;53(3):253-7.

15. daCosta DM, Paulose-Ram R, Su J, McDonald M, Zou KH, Wagner J-S, et al. The burden of chronic obstructive pulmonary disease among employed adults. Int J Chron Obstr Pulmonary Dis. 2012;7:211.

16. Thornton Snider J, Romley JA, Wong KS, Zhang J, Eber $\mathrm{M}$, Goldman DP. The disability burden of COPD. COPD. 2012;9(5):513-21.

17. May SM, Li JT, editors. Burden of chronic obstructive pulmonary disease: healthcare costs and beyond. Allergy and asthma proceedings: OceanSide Publications; 2015.

18. Rehman A, Hassali MAA, Muhammad SA, Harun SN, Shah S, Abbas $\mathrm{S}$. The economic burden of chronic obstructive pulmonary disease (COPD) in Europe: results from a systematic review of the literature. Eur J Health Econ. 2020;21(2):181-94. https://doi. org/10.1007/s10198-019-01119-1.

19. Rehman A, Hassali MAA, Abbas S, Ali IABH, Harun SN, Muneswarao J, et al. Pharmacological and non-pharmacological management of COPD limitations and future prospects: a review of current literature. J Public Health. 2019. https://doi.org/10.1007/ s10389-019-01021-3.

20. Quek D (ed). The Malaysian healthcare system: a review. Intensive workshop on health systems in transition. 2009; Kuala Lumpur.

21. Krol M, Papenburg J, van Exel J. Does including informal care in economic evaluations matter? A systematic review of inclusion and impact of informal care in cost-effectiveness studies. Pharmacoeconomics. 2015;33(2):123-35.

22. Goodrich K, Kaambwa B, Al-Janabi H. The inclusion of informal care in applied economic evaluation: a review. Value Health. 2012;15(6):975-81.

23. Department of Statistics Malaysia. Household Income \& Expenditure. 2019. Available at: https://www.dosm.gov.my/v1/index .php?r=column/ctwoByCat\&parent_id=119\&menu_id=amVoW U54UT10a21NWmdhMjFMMWcyZz09.

24. Exchange Rates, Central Bank of Malaysia. Government of Malaysia, Malaysia. Available at: https://www.bnm.gov.my/ index.php?ch $=$ statistic \&pg $=$ stats_exchangerates. Accessed 18 Sep 2019.

25. Quanjer PH, Stanojevic S, Cole TJ, Baur X, Hall GL, Culver BH, et al. Multi-ethnic reference values for spirometry for the 3-95-yr age range: the global lung function 2012 equations. Eur Respir J. 2012;40(6):1324-43.

26. Charlson ME, Pompei P, Ales KL, MacKenzie CR. A new method of classifying prognostic comorbidity in longitudinal studies: development and validation. J Chron Dis. 1987;40(5):373-83.

27. Cohen MD, Hawes DR, Hutchins GD, McPhee WD, LaMasters MB, Fallon RP. Activity-based cost analysis: a method of analyzing the financial and operating performance of academic radiology departments. Radiology. 2000;215(3):708-16.

28. Malaysia Go. Public Service Department. 2019. Available at: https ://www.jpa.gov.my/index.php?option=com_content\&view=artic le $\&$ id $=44 \% 3$ Acirculars-list $-2007 \&$ catid $=39 \% 3$ Acircular s-list\&lang=ms. Accessed Sep 2019.

29. Consumer Price Guide, Pharmaceutical Services Program, Ministry of Health Malaysia. Available at:. https://www.pharmacy.gov. my/v2/en/apps/drug-price. Accessed 1 Sep 2019.

30. WHO. Cost effectiveness and strategic planning, Word Health Organization. 2019. Available at: https://www.who.int/choice/ cost-effectiveness/inputs/capital_goods/en/. Accessed Sep 2019.

31. Atif M, Sulaiman SAS, Shafie AA, Asif M. Resource utilization pattern and cost of tuberculosis treatment from the provider and patient perspectives in the state of Penang, Malaysia. BMC Health Serv Res. 2014;14(1):353.

32. Barnes N, Calverley PM, Kaplan A, Rabe KF. Chronic obstructive pulmonary disease and exacerbations: patient insights from the global hidden depths of COPD survey. BMC Pulmonary Med. 2013;13(1):54.

33. Rehman A, Naeem F, Abbas S, Ashfaq F, Hassali MAA. Utilization of short message service (SMS) in non-pharmacological management of hypertension. A pilot study in an URBAN public hospital of Multan Pakistan. J Public Health. 2019;27(5):561-7.

34. Colás C, Brosa M, Antón E, Montoro J, Navarro A, Dordal M, et al. Estimate of the total costs of allergic rhinitis in specialized care based on real-world data: the FERIN Study. Allergy. 2017;72(6):959-66. 